\title{
A importância do uso da tecnologia assistiva na educação de surdos
}

\author{
The importance of using assistive technology in the education of the deaf \\ La importancia de utilizar tecnología de asistencia en la educación de sordos
}

Recebido: 20/02/2021 | Revisado: 27/02/2021 | Aceito: 08/03/2021 | Publicado: 16/03/2021

Evaldo Gabriel Nascimento da Silva ORCID: https://orcid.org/0000-0003-2502-5936 Universidade Federal do Pará, Brasil E-mail: g_silva@msn.com

Camila de Nazaré Araújo Cardoso

ORCID: https://orcid.org/0000-0003-3911-0584 Universidade Federal do Pará, Brasil E-mail: camilanacbio@gmail.com

\begin{abstract}
Resumo
Através de pesquisa bibliográfica qualitativa, o presente trabalho objetiva apresentar a importância das TIC's (Tecnologias da Informação e Comunicação) no processo de aprendizagem de alunos surdos, bem como estabelecer um paralelo entre elas e a educação à distância por meio de Ambientes Virtuais de Aprendizagem (AVA), como ferramenta complementar para diminuir a segregação e facilitar a aquisição de conhecimento e a comunicação de alunos do ensino básico. O educando surdo tem seu direito à educação garantido por uma série de leis e decretos, inclusive na escola regular. Essa inclusão, porém, não se dá satisfatoriamente, devido a inúmeros fatores, mas, principalmente, a falta de preparo dos agentes envolvidos e do desconhecimento das necessidades do surdo e ferramentas de que ele dispõe são fatores determinantes no pleno desenvolvimento educacional de alunos portadores de deficiência, em especial a surdez, foco desse estudo. Nesse contexto, Tecnologias Assistivas (TA), por meio das TIC's, surgem como importantes metodologias que se inserem no meio educacional oferecendo uma gama de ferramentas que proporcionam autonomia, independência e qualidade de vida no processo de inclusão de alunos surdos no ensino regular. Apesar de muitas problemáticas acerca do assunto, pode-se concluir que a TA é uma área do conhecimento eficaz para a melhoria da comunicação e do aprendizado de alunos surdos, facilitando também as relações entre si e com os ouvintes, daí a importância de estender seu uso para os processos educacionais.
\end{abstract}

Palavras-chave: Surdez; Inclusão; Tecnologias assistivas; TIC.

\begin{abstract}
Through qualitative bibliographic research, this paper aims to present the importance of ICTs (Information and Communication Technologies) in the learning process of deaf students, as well as to establish a parallel between them and distance education through Virtual Learning Environments (AVA), as a complementary tool to reduce segregation and facilitate the acquisition of knowledge and communication of primary school students. The deaf student has the right to education guaranteed by a series of laws and decrees, including in regular schools. This inclusion, however, does not occur satisfactorily, due to innumerable factors, but, mainly, the lack of preparation of the agents involved and the lack of knowledge of the needs of the deaf and the tools he has are determining factors in the full educational development of students with disabilities. disability, especially deafness, the focus of this study. In this context, Assistive Technologies (AT), through ICT's, appear as important methodologies that are inserted in the educational environment offering a range of tools that provide autonomy, independence and quality of life in the process of including deaf students in regular education. Despite many problems on the subject, it can be concluded that AT is an area of effective knowledge for improving communication and learning for deaf students, also facilitating relationships between themselves and with listeners, hence the importance of extending their use for educational processes.
\end{abstract}

Keywords: Deafness; Inclusion; Assistive technologies; ICT.

\section{Resumen}

Por medio de una investigación bibliográfica cualitativa, este trabajo tiene como objetivo presentar la importancia de las TIC (Tecnologías de la Información y la Comunicación) en el proceso de aprendizaje de los estudiantes sordos, así como establecer un paralelo entre ellas y la educación a distancia a través de Ambientes Virtuales de Aprendizaje (AVA), como herramienta complementaria para reducir la segregación y facilitar la adquisición de conocimientos y comunicación de los alumnos de primaria. El estudiante sordo tiene el derecho a la educación garantizado por una serie de leyes y decretos, incluso en las escuelas regulares. Esta inclusión, sin embargo, no se da de manera satisfactoria, debido a innumerables factores, pero, principalmente, la falta de preparación de los agentes involucrados 
y el desconocimiento de las necesidades de los sordos y las herramientas de que disponen son determinantes en el pleno desarrollo educativo de estudiantes con discapacidad, discapacidad, especialmente sordera, el tema central de este estudio. En este contexto, las Tecnologías Asistivas (TA), a través de las TIC, aparecen como importantes metodologías que se insertan en el entorno educativo ofreciendo un abanico de herramientas que brindan autonomía, independencia y calidad de vida en el proceso de inclusión de los estudiantes sordos en la educación regular. A pesar de muchos problemas sobre el tema, se puede concluir que la TA es un área de conocimiento eficaz para mejorar la comunicación y el aprendizaje de los estudiantes sordos, facilitando también las relaciones entre ellos y con los oyentes, de ahí la importancia de extender su uso para los procesos educativos.

Palabras clave: Sordera; Inclusión; Tecnologías de assistência; TIC.

\section{Introdução}

Conforme o Decreto $\mathrm{n}^{\circ} 5.626 / 2005$, Art. $2^{\circ}$, a pessoa surda é aquela que, por ter perda auditiva, compreende e interage com o mundo através de experiências visuais, manifestando sua cultura principalmente pelo uso da Língua Brasileira de Sinais (Libras). No que tange à deficiência auditiva, o Decreto considera aquela pessoa com perda bilateral, parcial ou total, de quarenta e um decibéis ou mais, aferida por audiograma nas frequências de $500 \mathrm{~Hz}, 1.000 \mathrm{~Hz}, 2.000 \mathrm{~Hz}$ e $3.000 \mathrm{~Hz}(\mathrm{Redação}$ dada pelo Decreto $n^{\circ} 5.626$, de 2005).

A Lei Brasileira de Inclusão da Pessoa com Deficiência - LBI (n ${ }^{\circ}$ 13.146/15) assegura e promove condições de igualdade, direitos e liberdades fundamentais, para pessoa com deficiência, visando à sua inclusão social e cidadania. Nada obstante, tornar essa inclusão mais eficaz no Brasil é um desafio, sobretudo, nas redes públicas de ensino.

Segundo os microdados do Censo Escolar de 2018 realizado pelo INEP (Instituto Nacional de Estudos e Pesquisas Educacionais Anísio Teixeira), 25.980 alunos surdos estão matriculados na educação especial no Brasil, representando 2,2\% das matrículas (Inep, 2018). Partindo do pressuposto de que muitos surdos só têm acesso à Libras quando chegam à escola, é pertinente se pensar em estratégias de aprendizagem que adotem políticas cada vez mais inclusivas no próprio ensino regular.

Nessa direção, políticas para a educação especial têm se destacado nas últimas décadas em prol da inclusão, onde se pode citar o desenvolvimento de TIC’s (Tecnologias de Informação e Educação) e os recursos de Tecnologia Assistiva (TA). Ainda em fase de construção em nosso país, a TA assume a definição de acordo com o Comitê de Ajudas Técnicas (Cat, 2007):

Uma área do conhecimento, de característica interdisciplinar, que engloba produtos, recursos, metodologias, estratégias, práticas e serviços que objetivam promover a funcionalidade, relacionada à atividade e participação de pessoas com deficiência, incapacidades ou mobilidade reduzida, visando sua autonomia, independência, qualidade de vida e inclusão social. (Cat, 2007, p.3)

No contexto das pessoas surdas ou com deficiência auditiva, podemos citar como exemplo de TA os aparelhos auditivos, celular com chamadas por vibração e mensagens escritas, aplicativos que traduzem as mensagens de texto em Libras, voz e texto fotografado. Recursos para tradução de conteúdos de áudio na TV analógica também fazem parte das ferramentas da TA, os quais são: a legendagem para surdos e ensurdecidos (LSE) e a Janela de Interpretação de Língua de Sinais (Figura 1).

Basicamente, a diferença entre esses dois recursos consiste em quão fluente na língua portuguesa o surdo é. Assim, o LSE atende as pessoas surdas que compreendem o português e a Janela de Interpretação de Língua de Sinais é direcionada para aqueles que não são fluentes na língua portuguesa. Assim:

Na LSE a tradução das falas de uma produção audiovisual em forma de texto escrito, podendo ocorrer entre duas línguas orais, entre uma língua oral e outra de sinais ou dentro da mesma língua. Por ser voltada, prioritariamente, ao público Surdo e Ensurdecido, a identificação de personagens e efeitos sonoros deve ser feita sempre que necessário. (Naves, et al., 2016, p. 10) 
A Janela de Interpretação de Língua de Sinais é definida como o espaço destinado à tradução entre uma língua de sinais e outra língua oral ou entre duas línguas de sinais, feita por Tradutor e Intérprete de Língua de Sinais (TILS), na qual o conteúdo de uma produção audiovisual é traduzido num quadro reservado, preferencialmente, no canto inferior direito da tela, exibido simultaneamente à programação. (Naves, et al., 2016, p. 10)

Figura 1 - Exemplos de Legendagem para Surdos e Ensurdecidos - LSE (esquerda) e Janela de Interpretação de Língua de Sinais (direita).
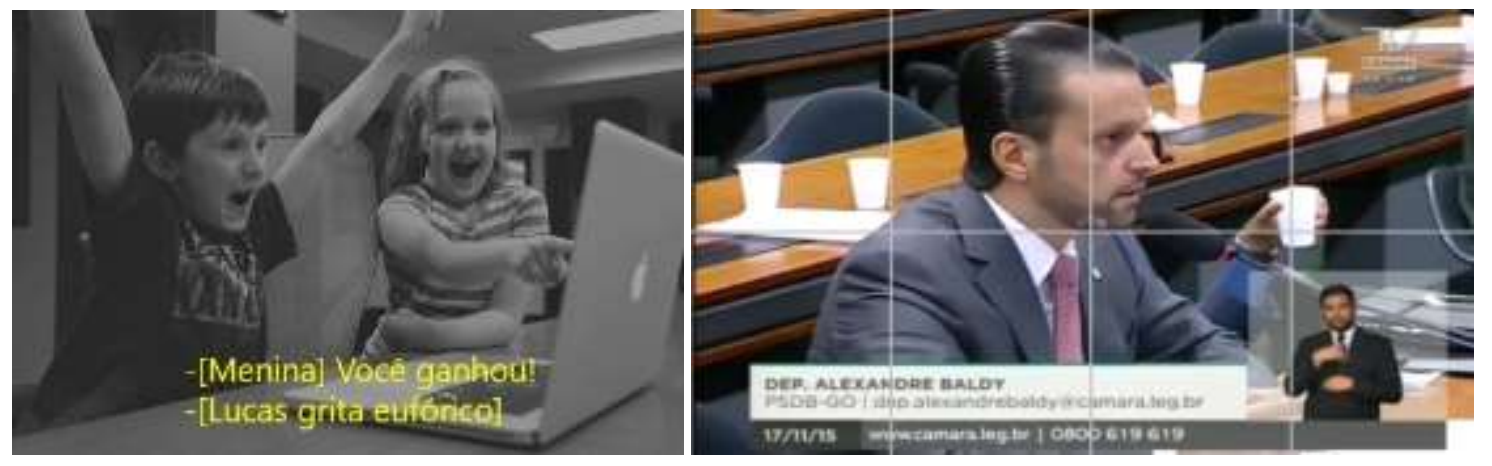

Fonte: Google Imagens.

França e Ono (2011) ressaltam que, comparativamente, a LSE é bem utilizada pelos canais de TV, enquanto que a janela de Libras ainda é pouco comum nas programações televisivas. Carvalho et al. (2017), sobre assunto comentam que, como nem todas as pessoas surdas dominam a Libras, a legendagem deve ser ofertada para que se garanta a igualdade no acesso aos conteúdos televisivos.

Alguns aspectos quanto ao uso da janela de Libras podem desagradar à pessoa surda pois, muitas vezes, o tamanho da janela é considerado pequeno, o que dificulta a compreensão do conteúdo televisivo (Secretaria Nacional de Justiça, 2009).

Além das traduções de conteúdos de áudio na televisão, existem os recursos para tradução para surdos disponibilizados em meio digital, que possibilitam que surdos e ouvintes de comuniquem de forma on-line. Conforme O’Connor, et al. (2017), esses recursos se dividem em três distintos grupos: 1) tecnologias dependentes de um intermediário; 2) tecnologias que utilizam um avatar; e 3) tecnologias de detecção de sinais.

As tecnologias que dependem de um intermediário configuram-se pela necessidade de um humano (intermediário) para estabelecer a comunicação. Por exemplo, surgido em 1964, o TeleTypewriter (TTY) (Figura 2), é uma máquina de escrever com telefone que permite aos surdos se comunicarem com ouvintes que não dispõem do dispositivo. 
Figura 2 - Telefone com TTY.

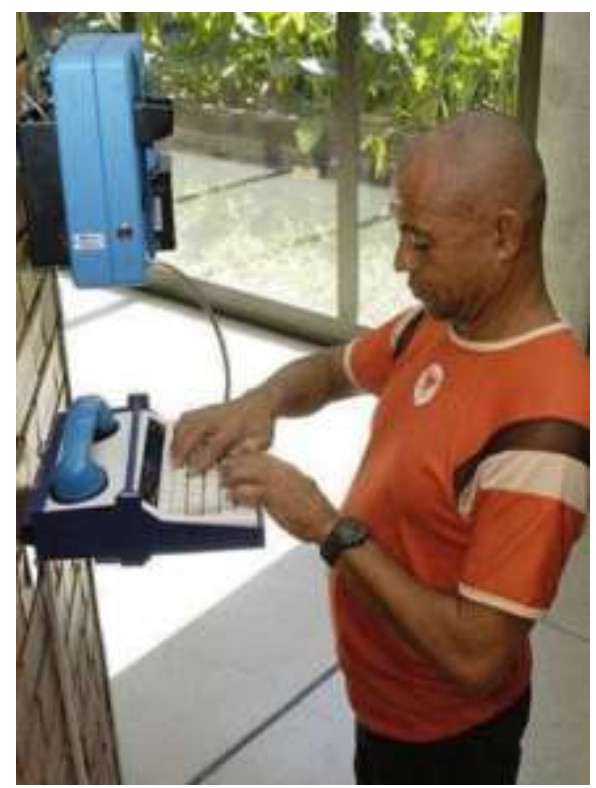

Foto: Ana Limp. Fonte: https://agencia.fiocruz.br/telefone-para-deficientes-auditivos-\%C3\%A9-instalado-na-fiocruz.

Esse aparelho conecta-se a um telefone transformando a mensagem datilografada em sinais elétricos e depois os retraduz em forma impressa para o interlocutor (Kirk \& Gallagher, 2000).

Outro exemplo de tecnologias dependentes de um intermediário são as videoconferências, onde há a presença de um tradutor de Libras on-line. A Secretaria Municipal da Pessoa com Deficiência e Mobilidade Reduzida de São Paulo (SMPED)/Central de Interpretação de Libras (CIL) desenvolveu o SMPEDCIL, um aplicativo gratuito para computadores e aparelhos móveis que consegue mediar a comunicação, em tempo real, entre a pessoa com surdez e o intérprete de Libras. Dessa forma, o indivíduo pode usar o aplicativo pode durante um atendimento em qualquer serviço público na cidade de São Paulo, mediante agendamento prévio (São Paulo, 2018).

Outro recurso que as TIC's oferecem através da internet, são os ambientes virtuais de aprendizado (AVA), bastante utilizados pelos cursos à distância que, segundo Pereira (2007, p. 4) “em termos conceituais, os AVA’s consistem em mídias que utilizam o ciberespaço para veicular conteúdos e permitir interação entre os atores do processo educativo". No contexto da TA, esses ambientes podem e devem ser inclusivos para alunos surdos pois, conforme Colacique (2013), AVA's devem possibilitar acesso ao conteúdo para que o estudante surdo possa se expressar, bem como produzir conhecimento A autora ressalta que somente a "hospedagem de vídeos para usuários surdos (Colacique, 2013, p. 90)” não é suficiente para que o ambiente seja considerado acessível.

Seguindo com os recursos digitais para tradução de conteúdos para surdos, as tecnologias que adotam avatares surgem com a comunicação realizada pela tradução de áudios e/ou textos em português para a Libras por intermédio de um avatar. A exemplo disso existem os aplicativos VLibras, Hand Talk, ProDeaf e Rybená (Figura 3), disponibilizados para diversas plataformas como softwares para computadores, plugins de navegadores de internet para tradução de sites e aplicativos para celular. 
Figura 3 - Aplicativos que usam avatar.

\begin{tabular}{|c|c|}
\hline & $\begin{array}{l}\text { VLibras, desenvolvido a partir da parceria entre Ministério do } \\
\text { Planejamento, Desenvolvimento e Gestão e a Universidade } \\
\text { Federal da Paraíba, a suíte VLibras é um conjunto de } \\
\text { ferramentas computacionais de código aberto, compatível com } \\
\text { computadores tradicionais e dispositivos móveis, que traduz } \\
\text { conteúdos digitais em formato de texto, áudio e vídeo para } \\
\text { Libras, com uso de um avatar. } \\
\text { Link: http://www.vlibras.gov.br/ }\end{array}$ \\
\hline Fonte: http://www.web & $\begin{array}{l}\text { O ProDeaf é um software que traduz texto e voz de português } \\
\text { para Libras, por intermédio de um avatar. Está disponível em } \\
\text { duas versões: o ProDeaf Móvel, aplicativo para smartphone, de } \\
\text { uso gratuito, e o ProDeaf WebLibras, solução paga que pode } \\
\text { ser incorporada diretamente a um site (pelo desenvolvedor) - o } \\
\text { que exime o usuário de fazer download para utilizá-lo naquele } \\
\text { site. } \\
\text { Link: http://www.prodeaf.net/ }\end{array}$ \\
\hline 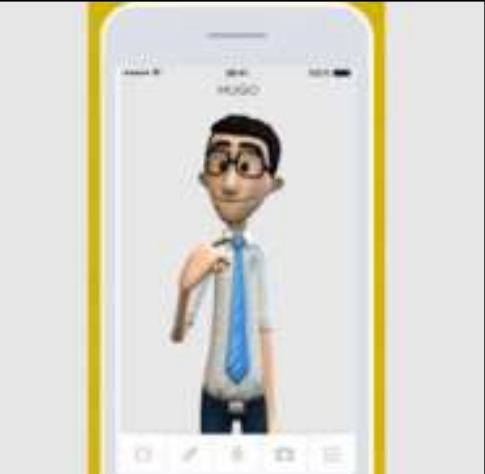 & $\begin{array}{l}\text { Hand Talk, Solução que realiza tradução digital e automática } \\
\text { para Libras, por meio de dois produtos principais: um tradutor } \\
\text { de sites pago, que deve ser incorporado no site pela } \\
\text { empresa/instituição mantenedora do site e um aplicativo para } \\
\text { celular gratuito, que traduz texto para Libras a partir de fala ou } \\
\text { digitação. No HandTalk o intérprete virtual é denominado } \\
\text { Hugo. Foi eleito em } 2013 \text { pela Organização das Nações Unidas } \\
\text { como o melhor app do mundo - na categoria "Inclusão Social". } \\
\text { (PORTAL G1, 2013). } \\
\text { Link: https://www.handtalk.me }\end{array}$ \\
\hline $\begin{array}{l}\text { Rybena } \\
-28\end{array}$ & $\begin{array}{l}\text { Rybená atualmente, possui duas versões: Web e Celular. O } \\
\text { Rybená Web, além traduzir textos de português para Libras, } \\
\text { possui um recurso que transforma o texto escrito em voz, o que } \\
\text { facilita a interação não apenas de surdos, mas também de } \\
\text { pessoas com deficiências visuais e intelectuais (ex.: síndrome } \\
\text { de down), analfabetos funcionais, idosos, disléxicos, e outras } \\
\text { pessoas com dificuldade de leitura e de compreensão de textos. } \\
\text { O Rybená para Web é pago e deve ser incorporado nos sites por } \\
\text { seus desenvolvedores/proprietários. } \\
\text { Link: http://portal.rybena.com.br }\end{array}$ \\
\hline
\end{tabular}

Fonte: Adaptado de Costa et al. (2019).

O uso desses aplicativos geram ainda bastantes discussões. Autores como Corrêa et al. (2014), Oliveira et al. (2017), e Rocha e Melgaço (2018) observam que o uso desses aplicativos pode contribuir para a autonomia da pessoa com surdez e, logo, facilitar sua inclusão e socialização. Entretanto, Colling e Boscarioli (2014) fazem críticas quanto à qualidade da tradução realizada, questionando a função desses aplicativos enquanto “intérpretes de Libras". 
De fato, existe uma gama de alternativas no âmbito das tecnologias assistivas, apoiadas nas TIC's que, dependendo do contexto, podem auxiliar no processo de aprendizagem de alunos surdos. Por esse motivo, quando voltamos seu uso para o contexto educacional, existe o apelo quanto a qualificação de profissionais que possuam qualificação adequada para intermediar o processo de ensino e aprendizagem do alunado surdo. As escolas, mais do que oportunizar o acesso à essas tecnologias, devem garantir também que professores estejam preparados para manusear os recursos de TA para enriquecer suas aulas.

Silva (2010) destaca que a autoria do professor, voltada para interatividade e aprendizagem coletiva, garantindo coautorias, através de atos de currículo movidos pela articulação de múltiplas informações e diálogo, é a chave para se promover inclusão efetiva dos estudantes e suas respectivas individualidades, ampliando suas redes formativas.

Para tanto, essa formação docente deve ser incentivada, uma vez que os recursos de TA estão em constante avanço e transformação, pois “o uso da tecnologia precisa preparar o próprio professor para viver a experiência de mudanças no ensino que ele proporcionará a seus alunos" (Alonso et al., 2014).

Usar as tecnologias em prol da educação especial pode significar para o aluno surdo verdadeiros avanços em sua formação educacional, bem além, na sua forma de interagir e se relacionar com seus iguais e ouvintes. De fato, "para as pessoas sem deficiência a tecnologia torna as coisas mais fáceis, para as pessoas com deficiência, a tecnologia torna as coisas possíveis" (Radabaugh, 1993).

Diante do exposto, o presente trabalho possui como princípio a concepção de que a educação inclusiva não se limita à inserção do aluno na escola, ou seja, apenas quando esses alunos são matriculados, mas implica em promover aos alunos com deficiência, bem como aos profissionais de educação, recursos e materiais pedagógicos, espaços etc., que garantam a aprendizagem de modo que venha a atender às limitações como um todo, de modo que promova as potencialidades desses educandos com o apoio das Tecnologias Assistivas.

Portanto, o presente trabalho objetiva discutir sobre a inclusão no contexto das tecnologias assistivas e, assim, apresentar os seus possíveis benefícios como auxílio no aprendizado de educandos com surdez.

\subsection{Revisão teórica}

\subsubsection{Compreendendo a educação especial}

A Lei de Diretrizes e Bases da Educação (LDB/96), atualizada no ano de 2018, conceitua educação especial como “a modalidade de educação escolar oferecida preferencialmente na rede regular de ensino, para educandos com deficiência, transtornos globais do desenvolvimento e altas habilidades ou superdotação.” (Redação dada pela Lei n 12.796, de 2013).

Nesse contexto, segundo a Lei Brasileira de Inclusão da Pessoa com Deficiência (Lei no 13.146, de 2015), considerase pessoa com deficiência aquela que tem impedimento de longo prazo de natureza física, mental, intelectual ou sensorial, o qual, em interação com uma ou mais barreiras, pode obstruir sua participação plena e efetiva na sociedade em igualdade de condições com as demais pessoas. O Caderno de Instruções do Censo Escolar (Inep, 2018), considerando critérios qualitativos do ponto de vista clínico, funcional e educacional, o público da educação especial é composto por alunos com deficiência física, deficiência auditiva/surdez, deficiência visual, deficiência intelectual, deficiência múltipla, surdocegueira, transtornos globais do desenvolvimento (TGD/TEA) e altas habilidades/superdotação. Deve-se compreender, por outro lado, que nem toda pessoa em situação de deficiência necessita de educação especial, mesmo que requeira tratamento terapêutico, habilitação ou reabilitação em função de suas especificidades.

A educação inclusiva compreende o processo de inclusão de alunos com deficiência bem como aqueles com distúrbios de aprendizagem, na rede comum de ensino e, conforme a Declaração de Salamanca (Unesco, 1994), “as crianças e jovens com necessidades educativas especiais devem ter acesso às escolas regulares, que a elas devem se adequar (...)" . 
A educação especial é entendida como:

Modalidade da educação escolar, entende-se um processo educacional definido por uma proposta pedagógica que assegure recursos e serviços educacionais especiais, organizados institucionalmente para apoiar, complementar, suplementar e, em alguns casos, substituir os serviços educacionais comuns, de modo a garantir a educação escolar e promover o desenvolvimento das potencialidades dos educandos que apresentam necessidades educacionais especiais, em todas as etapas e modalidades da educação básica. (Conselho Nacional de Educação, 2001, p. 1)

Dessa maneira, a educação especial atua em parceria com as escolas regulares, acompanhando e desenvolvendo estratégias que venham a favorecer o desenvolvimento dos alunos com deficiência.

As escolas possuem total responsabilidade de adequarem seu currículo, materiais, metodologias, etc., de forma a possibilitar a educação inclusiva, onde propiciem a inclusão em diferentes formas, atendendo as necessidades de todos os alunos. Mais do que trabalhar a inclusão para promover o acesso ao conhecimento de todos os alunos, a educação especial dentro do ensino regular da escola, favorece também a construção da cidadania, cada vez menos voltada para os conceitos de exclusão.

Na perspectiva dos direitos humanos, Leite et al. (2016), ao refletirem sobre a mudança de paradigmas acerca da pessoa com deficiência, apontam:

O modelo social propõe uma conceituação mais justa e adequada sobre as pessoas com deficiência, reconhecendo-as como titulares de direitos e dignidade humana inerentes, exigindo um papel ativo do Estado, da sociedade, e das próprias pessoas com deficiência. (Leite et al., 2016, p. 15)

A resolução do Conselho Nacional de Educação e Conselho de Educação Básica (CNE/CEB) n.2/2001, que instituiu as Diretrizes Nacionais para a educação especial na Educação Básica, recomenda em seu Art. $2^{\text {o. }}$

Os sistemas de ensino devem matricular todos os alunos, cabendo às escolas organizar-se para o atendimento aos educandos com necessidades educacionais especiais, assegurando as condições necessárias para uma educação de qualidade para todos. (Ministério de Educação e Cultura, 2001, p. 39-40)

Nota-se, desde então, a crescente preocupação dos governos em amparar as pessoas com deficiência criando e aprimorando legislações e decretos que vêm fortalecendo a educação especial no ensino regular. Em 2009, foi instituído a Resolução $n^{\circ} 4$ sobre as Diretrizes Operacionais para o Atendimento Educacional Especializado na Educação Básica, estabelecendo as formas possíveis de atendimento na educação especial:

Art. $1^{\circ}$ Para a implementação do Decreto $n^{\circ}$ 6.571/2008, os sistemas de ensino devem matricular os alunos com deficiência, transtornos globais do desenvolvimento e altas habilidades/superdotação nas classes comuns do ensino regular e no Atendimento Educacional Especializado (AEE), ofertado em salas de recursos multifuncionais ou em centros de Atendimento Educacional Especializado da rede pública ou de instituições comunitárias, confessionais ou filantrópicas sem fins lucrativos. (Resolução $n^{\circ} 4$ de 2 de outubro 2009, p. 17)

A implantação das salas de recursos multifuncionais partiu de uma iniciativa do Ministério da Educação, por meio da Portaria $\mathrm{n}^{\mathrm{o}} 13$ de 24 de abril de 2007, para incentivar o AEE dentro das escolas do ensino regular. A ideia de inclusão e intersetorialidade é ainda reforçada pela Política de Educação Especial na Perspectiva da Educação Inclusiva, de modo que:

[...] a transversalidade da modalidade de educação especial desde a educação infantil até a educação superior; oferta do atendimento educacional especializado; formação de professores para o atendimento educacional especializado e demais profissionais da educação para a inclusão; participação da família e da comunidade; acessibilidade 
arquitetônica, nos transportes, nos mobiliários, nas comunicações e informação; e articulação intersetorial na implementação das políticas públicas. (Redação dada pela Política de Educação Especial na Perspectiva da Educação Inclusiva, 2008, p. 15)

Pode-se observar a importância da oferta e formação de professores e profissionais para o AEE, uma vez que esse é um serviço que "identifica, elabora e organiza recursos pedagógicos e de acessibilidade, que eliminem as barreiras para a plena participação dos alunos [...]” (Política de Educação Especial na Perspectiva da Educação Inclusiva, 2008, p. 16). Vale ressaltar que esta é uma estratégia pedagógica em que as atividades devem ser diferentes das realizadas na sala de aula comum e, desta forma, não devem substituir a escolarização do aluno. Nesse sentido, o AEE é uma estratégia pedagógica que "complementa e/ou suplementa a formação do aluno, visando a sua autonomia na escola e fora dela, constituindo oferta obrigatória pelos sistemas de ensino.” (Ropoli et al., 2010, p. 17).

Em escolas da rede privada, a matrícula de alunos com deficiência é garantida sem que haja a cobrança de valores adicionais pela implementação de recursos de acessibilidade graças a Lei Brasileira de Inclusão da Pessoa com Deficiência (Lei n ${ }^{\circ}$ 13.146), promulgada em 2015, conhecida também como Estatuto da Pessoa com Deficiência.

A educação especial não tem sito uma tarefa fácil para nenhuma instituição educativa, assim como para seus profissionais que com ela tem se deparado, na grande maioria das vezes, sem formação para que possam melhor acompanhar esses alunos. Assim, a escola assume um importante papel nesse processo de apropriação de estratégias para a inclusão de alunos com deficiência, por meio de uma reestruturação nas suas políticas educativas de ensino, por meio da modificação nos mais diversos componentes escolares.

Pode-se afirmar que muitos desafios hoje enfrentados pela educação especial, de um modo geral, decorre de seu desenvolvimento histórico, uma vez que, no Brasil, a construção do atendimento educacional direcionado às pessoas com deficiência se deu de forma separada da educação oferecida às pessoas sem deficiência, onde a maior preocupação basicamente era diferenciar "normais" de "anormais", como mostra o trecho de um artigo publicado em 1914 no Brasil pelo italiano Ugo Pizzoli (1863-1934) em uma revista de educação da época:

O aspecto externo (atitude geral, a fisionomia, o vestuário, a postura espontânea) caracteriza e revela a condição psicológica da criança [...] O primeiro cuidado do professor será distinguir o typo inteligente normal médio do typo débil de espírito (imbecilidade, deficiências por paradas de desenvolvimento, atrasos, etc.). (Pizzoli, 1914, p. 2)

Desde a Constituição de 1988, que trouxe muitas mudanças para o ensino regular, observamos também transformações a respeito da educação especial, mesmo que, comparativamente, de forma mais lenta.

No cenário atual, presenciamos alguns pesquisadores usando termos como recursos pedagógicos adaptados, recursos de comunicação alternativa, acessibilidade e informática acessível, etc., para se referir ao que hoje, depois de diferentes terminologias utilizadas, chamamos de tecnologia assistiva, ou TA (Manzini, 2011).

De acordo com Carvalho e Manzini (2017), a tecnologia assistiva é uma área que se destaca por seus estudos voltados para a adaptação de estratégias para a aplicação de recursos com alunos com os mais diversos tipos de deficiência, de modo a ampliar ou fornecer acesso à informação, objetivando a melhoria nas condições humanas e promover a autonomia da pessoa com deficiência.

De fato, há muito o que se explorar no âmbito da educação especial, pois mesmo com todos os subsídios da legislação diante dos alunos com deficiência, é preciso ainda olhar além, ou seja, pensar práticas educativas que sejam transformadoras da realidade de quem tem de conviver com suas limitações. 


\subsubsection{A inclusão das pessoas surdas}

Ao se discutir a educação inclusiva de surdos, foco desse estudo, faz-se necessário levar em consideração o que é realmente necessário para que aconteça a inclusão em classes regulares, em termos não apenas de receber esses alunos, mas de ofertar subsídios, inclusive tecnológicos, que promovam o aprendizado e fortaleçam a comunicação e o acesso à informação. Os alunos surdos e/ou com deficiência auditiva adquirem linguagem da mesma forma que os alunos ouvintes, mas existe a necessidade de uma modalidade diferenciada que possibilite o pleno desenvolvimento desses alunos PcD.

Outro fator relevante é que muitos alunos surdos não são oralizados, só conhecem a Libras, ou são alfabetizados em língua portuguesa como segunda linguagem. Vale ressaltar que, de acordo com o Ministério da Educação, compete à Diretoria de Políticas de Educação Bilíngue de Surdos planejar, orientar e coordenar, em parceria com os sistemas de ensino voltados às pessoas surdas, com deficiência auditiva ou surdocegueira, e com as instituições representativas desse público, a implementação de políticas de educação bilíngue, que considerem a Libras, como primeira língua, e Língua Portuguesa Escrita, como segunda língua.

Dessa maneira, a inclusão dos alunos surdos nas escolas regulares é favorecida primariamente pelo uso do bilinguismo, que contribui bastante para o desenvolvimento desses alunos, visto que, muitas vezes, é na escola que se dá o primeiro contato com a Libras, já que a maioria dos surdos são filhos de pais ouvintes (Fernandes \& Moreira, 2014). Entendese que essa filosofia educacional garante meios mais satisfatórios de comunicação do aluno surdo na escola, em casa e com outros surdos, por outro lado, ela não deve ser vista como única opção no processo de ensino-aprendizagem, pois trata-se de apenas mais uma ferramenta que favorece o aprendizado e que deve ser utilizada em associação com outras metodologias de ensino, como por exemplo, para tradução de conteúdos digitais educativos.

Mesmo com a utilização do bilinguismo, os resultados em termos educativos para os alunos surdos não se demonstraram exatamente satisfatórios, pois há uma limitação no ensino, ou seja, a falta de compreensão dos significados da língua oral pelos alunos surdos, além da falta de qualificação profissional que atuam diretamente com esses alunos. Por tais condições, o processo de aprendizagem dos mesmos ocorre mais lentamente.

É nesse momento que o uso das tecnologias assistivas pode diminuir o espaço existente entre a inclusão garantida por lei, superando as limitações e, inclusive, auxiliando o processo de qualificação dos professores e outros envolvidos. Nesse contexto, de acordo com a Lei Brasileira de Inclusão da Pessoa com Deficiência, a TA é referida como: produtos, recursos, metodologias, praticas, serviços, equipamentos, dispositivos e estratégias que tenha objetivo de promover funcionalidade no indivíduo com deficiência ou mobilidade reduzida (Redação dada pela Lei nº 13.146, de 2015).

Vaz (2012) em seu estudo sobre o uso da tecnologia na educação do surdo na escola regular, chama a atenção para a importância do $\mathrm{EaD}$ (Educação a Distância), onde seu grande charme consiste no uso da tecnologia na promoção da autonomia, considerado atributo fundamental do processo de aprendizagem, somado a todas as suas vantagens, onde professores e alunos não estão juntos fisicamente, mas podem se conectar através dos recursos das TIC's por meio de videoconferências, chats, fóruns, etc. Observa-se que oferta de cursos EaD é embasada pelo Decreto $\mathrm{n}^{\circ} 9.057$, de 25 de maio de 2017, que regulamenta o art. 80 da Lei $n^{\circ}$ 9.394, de 20 de dezembro de 1996 (diretrizes e bases da educação nacional) e, em seu Art. $8^{\circ}$, autoriza a educação especial se utilizar dessa modalidade de ensino (Redação dada pelo Decreto $\mathrm{n}^{\circ}$ 9.057, de 2017).

A modalidade de ensino EaD se utilizada de ambientes virtuais de aprendizagem (AVA). Os AVA's são sistemas que ajudam os professores a gerenciar os conteúdos e acompanhar o desenvolvimento dos alunos. Para Almeida (2003), esses ambientes virtuais permitem integrar múltiplas mídias, linguagens e recursos, apresentar informações de maneira organizada, desenvolver interações entre pessoas e objetos de conhecimento, elaborar e socializar produções tendo em vista atingir determinados objetivos. 
Assim como toda ferramenta de aprendizagem, os AVA's também requerem adequação quanto o seu uso de acordo com o público que irá utilizá-los. No caso de alunos com surdez, esse recurso pode significar um verdadeiro diferencial na assimilação de conhecimento se estiver gerenciado por profissionais qualificados e que consigam trazer os conteúdos para a realidade do surdo se utilizando de todas as vantagens das TIC's.

Nessa perspectiva, deve-se criar um ambiente favorável e, para isso, é necessário que o sistema de educação disponibilize para a escola os recursos necessários. Frente a isso, não há inclusão quando consideramos que apenas o aluno seja sujeito a adaptar-se à escola, em especial os surdos, quando na verdade é a escola que deve oferecer subsídios para esse público.

\subsubsection{Como as tecnologias assistivas podem cooperar para a educação de surdos?}

Quando usamos o termo tecnologia, logo somos remetidos a ideia de máquinas, aparelhos, recursos audiovisuais, internet, etc., no entanto, quando falamos em tecnologias assistivas, ou simplesmente TA, temos que pensar além, pois são, na verdade, uma gama de conhecimentos interdisciplinares, artefatos, métodos e serviços que tem como objetivo promover a funcionalidade e a participação de PcD, incapacidades ou mobilidade reduzida, com a finalidade de prover independência, autonomia, qualidade de vida e inclusão social (Cat, 2007; Resolução no 4 de 2009).

Por ser interdisciplinar, a Tecnologia assistiva ganha nas TIC's novos recursos e produtos, que Galvão Filho et al. (2009) conceitua da seguinte forma:

Tecnologia Assistiva é uma área do conhecimento, de característica interdisciplinar, que engloba produtos, recursos, metodologias, estratégias, práticas e serviços que objetivam promover a funcionalidade, relacionada à atividade e participação de pessoas com deficiência, incapacidades ou mobilidade reduzida, visando sua autonomia, independência, qualidade de vida e inclusão social. (Galvão Filho et al., 2009, p. 26).

Quanto à população surda, as tecnologias assistivas desenvolveram-se como parte das transformações ocorridas na sociedade e no modo de se comunicar. Softwares foram criados para promover a comunicação entre surdos e ouvintes, como por exemplo o Hand talk, ProDeaf, Rybená, que são tradutores automáticos de língua portuguesa para Libras, que podem ser utilizados em páginas web e também em AVA's, facilitando o acesso as informações veiculadas nesses ambientes e favorecendo o aprendizado do aluno surdo. Semelhante a esses propósitos também existe o VLibras, que possui uma série de ferramentas, uma delas serve para a tradução de conteúdos de sites, áudios e textos para Libras e pode ser instalado em computadores, navegadores e celulares. Esses softwares utilizam um avatar 3D que faz a tradução em tempo real das palavras para a língua de sinais.

Saindo dos tradutores de Libras-Português, mesmo não estando disponíveis para o uso da população de modo geral, as tecnologias de detecção de sinais estão ainda em fase de pesquisa, buscando traduzir de maneira automática os gestos da língua de sinais através da utilização de luvas especiais ou câmeras de vídeo (O’Connor, et al., 2017; Wolk et al., 2017; Flores, et al., 2012).

Basicamente, a tecnologia que utiliza luvas especiais (Figura 4) contam com sensores que captam e registram os movimentos realizados pelas mãos, transmitindo essas informações para um computador. Lá os dados são analisados e, partindo de um banco de dados, o computador identifica a palavra que corresponde ao gesto analisado. Em contrapartida, essa tecnologia não captura elementos gramaticais das expressões faciais, como a movimentação dos olhos, sobrancelhas, boca, cabeça, tronco e etc., que são importantes para a entonação das palavras (Flores, et al., 2012). 
Figura 4 - Luvas SignAloud.

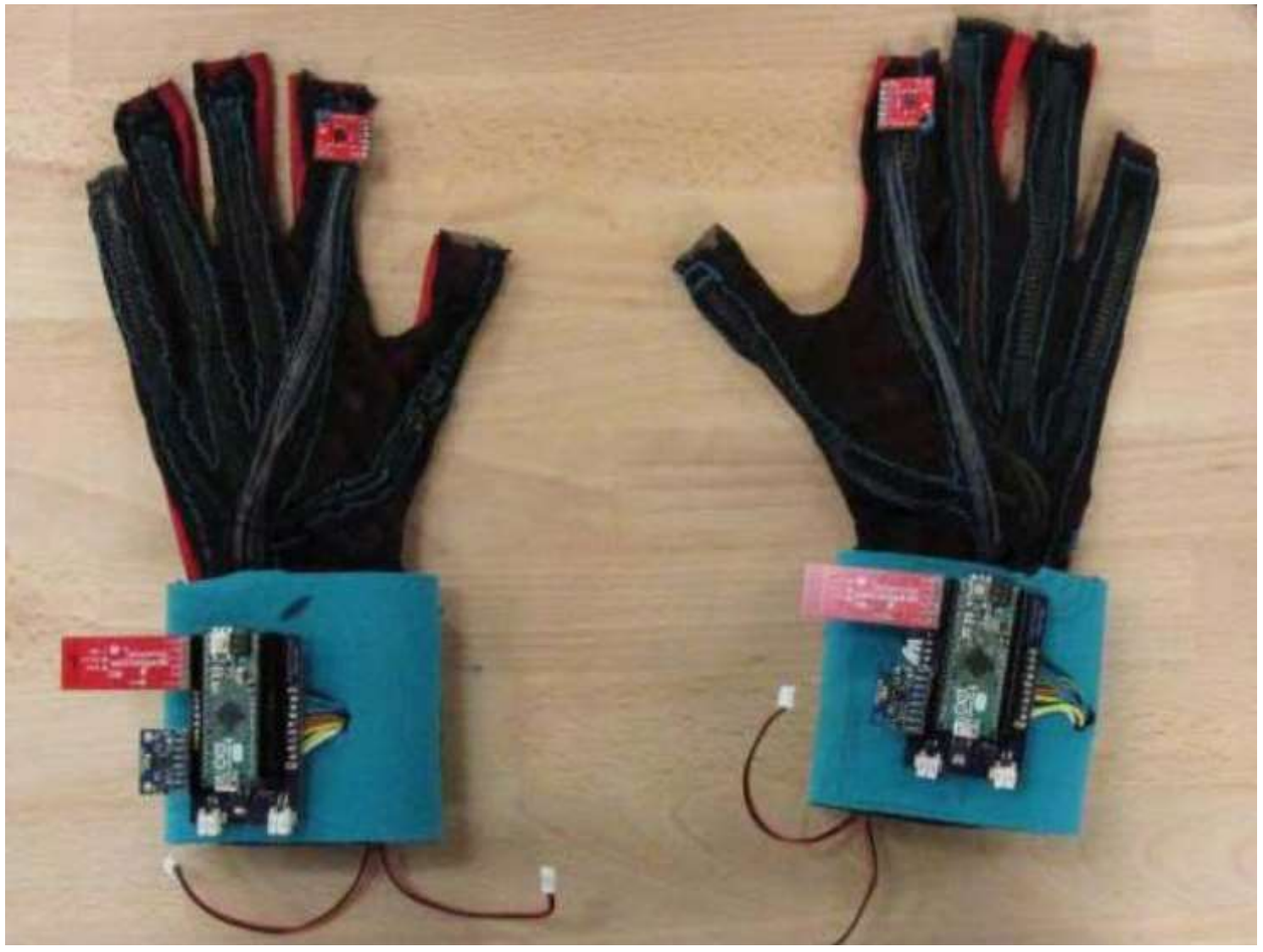

Fonte: https://atlasofthefuture.org/project/signaloud/.

Dentre os dispositivos de fácil acesso que podem favorecer a educação de surdos, tem-se também os dicionários de Libras, que atualmente são inúmeros, podendo ser digitais ou impressos, disponíveis em CD-ROM ou na internet. Para Klimsa (2016), os dicionários digitais possuem as mesmas as mesmas informações daqueles impressos e sua principal vantagem é a rapidez no acesso às informações e no cruzamento de informações dentro do dicionário. Visto vez que a língua de sinais de desenvolve no espaço, dotada de movimento, configuração e localização como parâmetros fonológicos sincrônicos, a concepção dos dicionários digitais possibilita a visualização em tempo real dos sinais, uma vez que são filmados, organizados e descritos de forma como a língua acontece de fato (Klimsa, 2016).

A internet destaca-se, desde a sua criação, como uma das mais importantes ferramentas no auxílio da aprendizagem, interligando pessoas e permitindo a disseminação de informações. Nesse sentido, a EaD aparece como uma possibilidade de inclusão, uma vez que essa modalidade inovadora de ensino utiliza a internet para transmitir conhecimento fazendo uso de imagens, textos, vídeos interativos, etc.

No Brasil, a fim de garantir o acesso digital a todos de forma inclusiva, criou as normas de Acessibilidade do Governo Eletrônico (e-MAG), que é um conjunto de recomendações que devem ser seguidas para que não existam barreiras digitais nas páginas web, e com isso, as oportunidades de acesso aos serviços e informações do governo sejam as mesmas para todos os brasileiros, quer tenham alguma deficiência ou não.

Para a educação de nível básico, as tecnologias assistivas podem estar presentes de muitas maneiras se a escola buscar oferecer, por exemplo, computadores com softwares interativos para surdos, dicionários de libras, intérpretes, fazer uso de Legendagem para Surdos e Ensurdecidos (LSE) e Janela de Interpretação de Língua de Sinais. No contexto de TA, esses são recursos que facilitam a aprendizagem e promovem a independência do aluno surdo. No entanto, investir somente em recursos 
não basta, é preciso se atentar também para os serviços, pois é importante qualificar a equipe escolar, especialmente os professores, uma vez que estes devem fazer das tecnologias assistivas uma valiosa ferramenta pedagógica.

A aplicabilidade da TA requer não somente o domínio dos recursos por parte dos educadores, mas também que eles sejam capazes de desenvolver metodologias e estratégias que levem em consideração as necessidades dos educandos, aproximando-os da sua realidade durante o processo de ensino-aprendizagem.

Nesse contexto, o professor é responsável por criar um ambiente interdisciplinar de aprendizagem, instigando seus alunos, propondo desafios e explorações que conduzam às descobertas na construção do conhecimento fazendo uso de computadores e seus softwares para problematizar os mais diversos assuntos.

\section{Metodologia}

Este estudo se trata de uma pesquisa bibliográfica que, segundo Marconi \& Lakatos (1992, p. 44), é o levantamento da bibliografia já publicada em livros, revistas, publicações avulsas e imprensa escrita. Possui como finalidade permitir que pesquisador entre em contato direto com todo o material escrito sobre um assunto escolhido, auxiliando na análise de suas pesquisas ou na manipulação de suas informações, sendo considerada como o primeiro passo de toda a pesquisa científica.

Com abordagem qualitativa, este estudo pauta-se na descrição subjetiva dos dados sobre a utilização das TIC's na educação de surdos. Considerando sua natureza complexa, Minayo (1994, p. 21-22), afirma que:

A pesquisa qualitativa responde a questões muito particulares. Ela se preocupa, nas ciências sociais, com um nível de realidade que não pode ser qualificado, ou seja, ela trabalha com o universo de significados, motivos, aspirações, crenças, valores e atitudes, o que corresponde a um espaço mais profundo das relações, dos processos e dos fenômenos que não podem ser reduzidos a operacionalização de variáveis. (Minayo, 1994, p. 21-22)

Foi com base nessas informações que as investigações aconteceram e, nesse processo, os conteúdos dos materiais investigados contribuíram para que se construíssem os conhecimentos apresentados no presente trabalho.

\section{Resultados e Discussão}

Para Veloso e Rabelo (2018), por serem recentes as produções teórico-metodológicas relacionadas à pedagogia visual na área dos surdos, elas ainda são pouco exploradas, mesmo que a língua de sinais seja ancorada nos recursos de imagem visual.

De fato, a criação de softwares que facilitam a comunicação entre ouvintes e pessoas com surdez são verdadeiros incrementos no processo de aprendizagem. No mercado existem muitos tradutores de Libras para língua portuguesa e, como os citados no presente estudo, o Hand talk, ProDeaf, Rybená e VLibras, são aplicativos apontados por Rocha e Melgaço (2018) que podem ajudar na ampliação do vocabulário de pessoas surdas e ouvintes, através de consultas ao dicionário.

Contudo, os mesmos autores detectaram problemas nesses softwares quanto a tradução do português pelos avatares, uma vez que o sinal de cada palavra é realizado separadamente, ou seja, sem uma tradução da frase inteira, o que gera confusão quanto o que está sendo interpretado.

Problemas semelhantes também foram observados por Colling e Boscarioli (2014) nos aplicativos Rybená, Hand Talk e ProDeaf. De acordo com os autores, foi observado dificuldades de na realização de uma tradução automática lógica e coerente devido à diferença estrutural da língua, além de apresentarem expressões faciais ausentes ou pouco claras, bem como o regionalismo de alguns sinais utilizados.

Dessa forma, evidencia-se que o uso de avatares em aplicativos tradutores de Libras-Português não se assemelha e nem substitui um humano. Embora, muitas vezes, esses avatares estarem mais facilmente disponíveis e acessíveis do que um 
intérprete de Libras ou ouvinte proficiente de Libras, enfatiza-se que seu uso precisa ser revisto e aprimorado constantemente pelos desenvolvedores. De um modo geral, acredita-se os avatares contribuam para a aprendizagem em um ambiente que utilize textos/falas mais gerais e básicos do que técnicos.

Dessa maneira, os alunos $\mathrm{PcD}$ contam com ajudas técnicas para a realização de sua inclusão, que são: qualquer elemento que facilite a autonomia pessoal ou possibilite o acesso e o uso do meio físico (Redação dada Lei $n^{\circ} 10.098$, de 2000). Hoje, mais do que oferecer assistência às necessidades individuais dos alunos com deficiência, o uso do computador e afins pode e deve auxiliar no desenvolvimento do potencial cognitivo, criativo, linguístico, comunicacional e sócio afetivo dessas crianças, jovens e adultos.

Salienta-se que é o processo de mediação pedagógica que pode definir a forma de utilização das tecnologias. Segundo os conceitos de tecnologias assistivas, para aplicar tecnologia na educação especial é necessário, antes de tudo, conhecer o usuário, e modelar o ambiente, que inclui a proposta pedagógica, ajudas técnicas e adaptativas.

Segundo o trabalho de Costa (2011) sobre o uso da informática na educação de surdos, demonstrou-se que a maioria dos professores ainda usa muito pouco os recursos tecnológicos. Podemos estender esses resultados à realidade das tecnologias assistivas, uma vez que para manusear os recursos e desenvolver estratégias de aprendizagem para surdos é requerido qualificação por parte desses profissionais, uma vez que são eles os mediadores desse processo.

Fachinetti e Carneiro (2017) pontuam que a formação de profissionais não é o único empecilho para que se efetivem ações que favoreçam o uso da TA como facilitadora do processo de inclusão educacional. Os autores afirmam que é imprescindível a necessidade de se conceituar especificamente as tecnologias assistivas para que se direcione melhor as opções de serviço e principalmente financiamentos.

De fato, quando a escola estabelece objetivos que primem por uma educação inclusiva, desde o seu currículo até sua infraestrutura, é dela a responsabilidade de adquirir recursos e serviços de TA que devem ser constantemente atualizados e aperfeiçoados, uma vez que o processo de aprendizagem é dinâmico em sua essência, não podendo os alunos com deficiência auditiva/surdez ficarem a margem desse processo.

Inserida no ensino regular, a educação especial também deve estar voltada para a interdisciplinaridade, focada não só no aprendizado de conteúdos, mas também deve estar empenhada em formar para a vida, adultos que possam exercer sua cidadania de forma independente onde a comunicação nunca seja um empecilho para o acesso à informação.

Fica evidente que os alunos ganham autonomia, mais claramente desenvolvendo suas atividades e o aprendizado individualizado se tornam mais criativos, graças a grande variedade de ferramentas disponíveis, entre software e hardware dos computadores. É fato que a distribuição eficaz de dispositivos de tecnologia assistiva depende de avaliações competentes e, nesse sentido, De Witte et al. (2018) afirmam que a padronização com base em um modelo conceitual e em instrumentos de avaliação poderia possibilitar a comparação de serviços e os resultados obtidos, assim como verificar o impacto das políticas existentes para o desenvolvimento de novas políticas sejam norteados.

Ao manusear, por exemplo, um computador no ambiente educacional, o aluno surdo traz consigo o elemento motivacional para o seu processo de desenvolvimento. Com isso, o ambiente mais enriquecedor que as tecnologias têm proporcionado possibilita que esses alunos tenham uma interação maior e de melhor qualidade com o mundo a sua volta.

Carvalho e Manzini (2017) em seu estudo sobre aplicação de realidade aumentada no ensino de surdos, observaram que as aplicações desse tipo de tecnologia assistiva poderá propiciar a interação e o aperfeiçoamento da língua de sinais, podendo se tornar um recurso aplicável em ambientes inclusivos, no qual possibilitará o ensino de Libras para alunos sem surdez, beneficiando seus pares, alunos com surdez.

Utilizar tais ferramentas para a inclusão pode ser um grande avanço em facilitar e socializar os conhecimentos e, principalmente, sua produção, inclusive dos culturalmente excluídos e que por hora ficaram reféns do desconhecido. 
Dessa forma, a maneira como são usados os recursos tecnológicos, especialmente o computador, na inclusão escolar pode vir a garantir igualdade de oportunidades e não desvalorizar o potencial dos alunos surdos.

\section{Considerações Finais}

Através da pesquisa bibliográfica foi possível compreender o impacto que as tecnologias podem causar no contexto educacional do surdo e, mesmo diante de tantas legislações e contribuições acerca do assunto na literatura no que se refere o uso das tecnologias assistivas, ainda existe a necessidade de se repensar as metodologias nessa área do conhecimento voltadas para educação especial. No âmbito da educação de surdos, existe uma série de melhorias a serem realizadas como, por exemplo, nos tradutores digitais, especialmente os que utilizam avatares, uma vez que questões como o regionalismo podem ser um fator determinante no entendimento dos conteúdos.

É necessário ter discernimento ao lançar mão desses aplicativos, não descartando seu uso, mas considerando o contexto em que o aluno surdo se encontra, talvez, auxiliando em aulas que não utilizem muitos termos técnicos para não gerar confusão na compreensão do que está sendo traduzido.

Nessa mesma linha, os AVA's têm se difundido cada vez mais na educação de modo geral, sobretudo em cursos EaD, logo, esses ambientes também devem estar aptos a atender a comunidade surda, desde o ensino básico, promovendo interação e autonomia no público alvo.

Os dicionários bilíngues, impressos e digitais, parecem ser uma boa opção para auxiliar no processo de ensinoaprendizagem de surdos, nada obstante, também requerem cuidados, pois esse recurso precisa ser funcional em termos científicos e práticos para um público com uma variedade de sujeitos. Para tal, é preciso considerar que a comunidade de surda é dotada de uma cultura que precisa ser valorizada.

Assim, observamos que tem se difundido muito mais o conceito de integração do que inclusão e, na maioria das vezes, é forçada, em um processo que não dispõe realmente de ferramentas que possibilitem aprimorar estratégias que garantam o desenvolvimento dos alunos deficientes, em especial os surdos. É importante lembrar que o sentido de integrar divide com esses alunos a responsabilidade de inserção, enquanto a inclusão busca avançar, exigindo também da sociedade, condições para essa inserção. Nesse sentido, claramente, a inclusão sem os devidos cuidados pode se tornar uma forma de exclusão.

Desse modo, acreditamos que dominar os conceitos e as práticas dessa área do conhecimento pelos agentes envolvidos no processo educacional trará vantagens positivas no acesso, autonomia e independência do alunado surdo, facilitando não somente o aprendizado, mas a maneira de se relacionar com os diversos grupos sociais, ouvintes ou não ouvintes. Embora ainda haja muitas lacunas e necessidades a serem sanadas no âmbito do uso de tecnologias assistivas no ensino regular, a apropriação da TA através das TIC's permite compreender que é possível utilizar essas ferramentas para um fim específico: a educação.

Portanto, estudos sobre essa temática se fazem necessários para dar continuidade as discussões, especialmente ao que diz respeito à formação continuada dos profissionais da educação, o papel das políticas públicas, bem como a oferta de recursos tecnológicos necessários para serem utilizados de acordo com as especificidades dos estudantes no sentido de não somente oportunizar a sua disponibilização, mas que também estimulem a fiscalização de modo a garantir a sua utilização para contribuir no processo de ensino-aprendizagem de alunos surdos.

\section{Referências}

Almeida, M. E. B. (2003). Educação a distância na internet: abordagens e contribuições dos ambientes digitais de aprendizagem. Educação e Pesquisa, 29(2), 327-340. https://www.scielo.br/pdf/ep/v29n2/a10v29n2.pdf. 
Alonso, K. M., Aragón, R., Silva, D. G. da., \& Charkzuk, C. B. (2014). Aprender e ensinar em tempos de cultura digital. Revista de Educação a Distância, $1(1), 152-168$.

Basas, M. M., \& Pagliaro, C. M. (2014). Technology use among adults who are deaf and hard of hearing: a national survey. Journal of Deaf Studies and Deaf Education, 19(3), 400-410.

Carvalho, D., \& Manzini, E. J. (2017). Aplicação de um programa de ensino de palavras em libras utilizando tecnologia de realidade aumentada. Revista Brasileira de Educação Especial, 23(2), 215-232.

Carvalho, F. C. M., Souza, M. C. de., Alves, O. P. da S., \& Leonel, W. H. dos S. (2017, 17 a 21 de setembro). Legendas no processo ensino aprendizagem na educação inclusiva na modalidade a distância. [Anais]. Congresso internacional ABED de educação a distância, Foz do Iguaçu. http://www.abed.org.br/congresso2017/trabalhos/pdf/36.pdf.

Cat. (2007). Comitê de ajudas técnicas. Cat, 5. 2007. Brasília. Ata de Reunião. Brasília: Cat, Corde; Sedh, 2007.

Colacique, R. (2013). Acessibilidade para surdos, na cibercultura: os cotidianos nas redes e na educação superior online [Dissertação de Mestrado, Universidade do Estado do Rio de Janeiro]. http://www.bdtd.uerj.br/tde_busca/arquivo.php?codArquivo=6603.

Colling, J. P., \& Boscarioli, C. (2014). Avaliação de tecnologias de tradução português-libras visando o uso no ensino de crianças surdas. RENOTE, 12(2), 1100.

Corrêa, Y., Vieira, M. C., Santarosa, L. M. C., Biasuz, M. C. V. (2014). Tecnologia Assistiva: a inserção de aplicativos de tradução na promoção de uma melhor comunicação entre surdos e ouvintes. RENOTE, 12(1), 1-10. Recuperado de: https://seer.ufrgs.br/renote/article/view/49824.

Costa, M. S. O. (2011). Os benefícios da informática na educação dos surdos. Momento, 20(1), 101-122.

Costa, V. M., Sacramento, C., Barbosa, P. G. F., \& Alves, A. da S. (2019). Tecnologias Assistivas. Parte II. Módulo 4. Rio de Janeiro: Fiocruz/Icict. https://mooc.campusvirtual.fiocruz.br/rea/acessibilidade-sus/downloads/modulo_4/Apostila-acessivel_mod4_parte2.pdf.

De Witte, L., Steel, E., Gupta, S., Ramos, V. D., \& Roentgen, U. (2018). Assistive technology provision: towards an international framework for assuring availability and accessibility of affordable high-quality assistive technology. Disability and Rehabilitation: Assistive Technology, 13(5), 467-472. https://www.tandfonline.com/doi/pdf/10.1080/17483107.2018.1470264?needAccess=true.

Decreto 5.626 de 2005 [Ministério da educação]. Regulamenta a Lei no 10.436, de 24 de abril de 2002, que dispõe sobre a Língua Brasileira de Sinais - Libras, e o art. 18 da Lei $\mathrm{n}^{\circ} 10.098$, de 19 de dezembro de 2000. 22 de dezembro de 2005.

Decreto $\mathrm{n}^{\circ}$ 9.057, de 25 de maio de 2017. [Ministério da Educação e do Desporto]. Regulamenta o art. 80 da Lei n 9.394 , de 20 de dezembro de 1996, que estabelece as diretrizes e bases da educação nacional. 26 de maio de 2017.

Fachinetti, T. A., \& Carneiro, R. U. C. (2017). A tecnologia assistiva como facilitadora no processo de inclusão: das políticas públicas a literatura. Revista on line de Política e Gestão Educacional, 21(n. esp. 3), 588-1597.

Fernandes, S., \& Moreira, L. C. (2014). Políticas de educação bilíngue para surdos: o contexto brasileiro. Educar em Revista, ed. esp. (2),51-69.

Flores, E. M., Barbosa, J. L. V., \& Rigo, S. J. (2012). Um estudo de técnicas aplicadas ao reconhecimento da língua de sinais: novas possibilidades de inclusão digital. Renote, 10(3), 1-10.

França, A. C. C. V., \& Ono, M. M. (2011). Interação de pessoas surdas mediada por sistemas de produtos e serviços de comunicação. Cadernos Gestão Pública e Cidadania, 16(59), 260-276. Recuperado de: http://bibliotecadigital.fgv.br/ojs/index.php/cgpc/article/viewFile/3749/2353.

Galvão Filho, T. A. (2009). A Tecnologia Assistiva: de que se trata? In G. J. C. Machado, \& M. N. Sobral, M. N. (Eds.), Conexões: educação, comunicação, inclusão e interculturalidade. 207-235. Redes Editora. http://www.galvaofilho.net/assistiva.pdf.

Gil, A. C. (1999). Métodos e técnicas de pesquisa social. Atlas.

Inep. (2018). Instituto Nacional de Estudos e Pesquisas Educacionais Anísio Teixeira. Censo Escolar da Educação Básica - Caderno de Instruções, 2018. Recuperado de: http://download.inep.gov.br/educacao_basica/educacenso/situacao_aluno/documentos/2018/caderno_de_instrucoes-censo_escolar2018.pdf.

Kirk, S. A., \& Gallagher, J. J. (1996). Educação da criança excepcional. Martins Fontes.

Klimsa, S. B. de F. (2016). Proposta de Dicionário Infantil Bilíngue Libras/Português [Tese de Doutorado, Universidade Federal da Paraíba]. https://repositorio.ufpb.br/jspui/handle/123456789/11628.

Lei n ${ }^{\circ} 12.796$ de 2013. Institui as Diretrizes e Bases da Educação. 04 de abril de 2013. DO No. 65.

Lei $n^{\text {o }} 10.098$ de 2000. Estabelece normas gerais e critérios básicos para a promoção da acessibilidade das pessoas portadoras de deficiência ou com mobilidade reduzida, e dá outras providências. 19 de dezembro de 2000. DO eletrônico.

Lei n ${ }^{\circ} 13.146$ de 2015. Institui a Lei Brasileira de Inclusão da Pessoa com Deficiência. 6 de julho de 2015. DO No. 127

Lei nº 9.394 de 1996. [Ministério da Educação]. Estabelece as diretrizes e bases da educação nacional. 20 de dezembro de 1996.

Leite, F. P. A., Ribeiro, L. L. G., \& Costa Filho, W. M. (2016). Comentários ao Estatuto da Pessoa com Deficiência. São Paulo: Editora Saraiva.

Manzini, E. J. (2011). Formação de Professores e Tecnologia Assistiva. In K. R. M. Caiado, D. M. Jesus, \& C. R. Baptista (Eds.), Professores e educação especial: formação em foco (2a ed.), 45-63. Editora Mediação. 
Marconi, M. A., \& Lakatos, E. M. (19920. Metodologia do trabalho científico. Editora Atlas.

Ministério da Educação. Política Nacional de Educação Especial na perspectiva da Educação Inclusiva. 7 de janeiro de 2008.

Naves, S. B., Mauch, C., Alves, S. F., Araújo, V. L. S. (2016). Guia para produções audiovisuais acessíveis. https://inclusao.enap.gov.br/wpcontent/uploads/2018/05/Guia-para-Producoes-Audiovisuais-Acessiveis-com-audiodescricao-das-imagens-1.pdf.

O’Connor, T.F, Fach, M. E., Miller, R., Root, S. E., Mercier, P. P., \& Lipomi, D. J. (2017). The Language of Glove: Wireless gesture decoder with lowpower and stretchable hybrid electronics. PLoS ONE, 12(7), 1-12. https://journals.plos.org/plosone/article?id=10.1371/journal.pone.0179766.

Oliveira, R. S., Cruz, R. L.S., \& Magalhães, R. J. (2017). Uma análise sobre o aplicativo VLibras: (im)possibilidade de ser instrumento para efetivação da inclusão social via acessibilidade digital. [Anais]. $4^{\text {a }}$ Congresso Internacional Direito e Contemporaneidade: mídias e direitos da sociedade em rede, Santa Maria. http://coral.ufsm.br/congressodireito/anais/2017/9-1.pdf.

Pádua, E. M. M. (1997). Metodologia da pesquisa: abordagem teóricoprática. Papiros.

Pereira, A. T. C. (2007). Ambientes Virtuais de Aprendizagem em Diferentes Contextos. Ciência Moderna.

Pizzoli, U. (1914). Psychologia Pedagogica. Revista de Ensino. Transcrição autorizada pelo autor do Estado de S. Paulo. Ano XIII, n. 3, dez.

Portaria n 13 de 2007 [Ministério da Educação]. Dispõe sobre a criação do Programa de Implantação de Salas de Recursos Multifuncionais. 24 de abril de 2007.

Radabaugh, M. P. (1993). Study on the Financing of Assistive Technology Devices of Services for Individuals with Disabilities: A report to the president and the congress of the United State, National Council on Disability. http:// https://www.ncd.gov/publications/1993/Mar41993.

Resolução nº 2 de 2001 [Conselho Nacional de Educação e Conselho de Educação Básica]. Institui Diretrizes Nacionais para a Educação Especial na Educação Básica. 14 de setembro de 2001. http://portal.mec.gov.br/cne/arquivos/pdf/CEB0201.pdf.

Resolução nº 4 de 2009 [Ministério da Educação]. Institui Diretrizes Operacionais para o Atendimento Educacional Especializado na Educação Básica, modalidade Educação Especial. 2 de outubro de 2009.

Rocha, C., \& Melgaço, S. C. (2018, 9 a 11 de maio). O uso de aplicativos para tradução de Libras. [Anais]. V Simpósio Internacional de Inovação em Mídias Interativas. Goiânia. https://siimi.medialab. ufg.br/up/777/o/4_-_Sarah_Melgaco.pdf.

Ropoli, E. A., Mantoan, M. T. E., Santos, M. T. C. T., \& Machado, R. (2010). A Educação Especial na Perspectiva da Inclusão Escolar: a escola comum inclusiva. Brasília: Ministério da Educação, Secretaria de Educação Especial; Fortaleza: Universidade Federal do Ceará, 2010. (Coleção A Educação Especial na Perspectiva da Inclusão Escolar).

Secretaria Nacional de Justiça. (2009). A classificação indicativa na língua brasileira de sinais. Brasília: SNJ. http://www.justica.gov.br/seusdireitos/classificacao/classificacaolinguasinais.pdf.

Silva, M. (2010). Sala de aula interativa. Loyola.

UNESCO. (1994). Declaração de Salamanca e Linha de Ação sobre Necessidades Educativas Especiais. Brasília: CORDE.

Vaz, V. M. (2012). O Uso da Tecnologia na Educação do Surdo na Escola Regular. [Monografia, Faculdade de Tecnologia de São Paulo]. http://www.fatecsp.br/dti/tcc/tcc00073.pdf.

Veloso, R. N. S., \& Rabelo, L. C. C. (2018, 17 a 19 de outubro). O uso de tecnologia assistiva no processo de letramento de surdos. [Anais]. $5^{\circ}$ Congresso Paraense de Educação Especial, Marabá. https://cpee.unifesspa.edu.br/images/ANAIS_VCPEE/COMUNICACAO_ORAL/OUSODETECNOLOGIA.pdf.

Wolk, K., Wolk, A., \& Glinkowski, W. (2017). A Cross-Lingual Mobile Medical Communication System Prototype for Foreigners and Subjects with Speech, Hearing, and Mental Disabilities Based on Pictograms. Hindawi, 2017,1- 9. https://www.hindawi.com/journals/cmmm/2017/4306416/. 